\title{
Surveillance of Major Canine Pathogens in Feral Dogs and Big Cats at the Domestic-Wildlife Interface in Panna Tiger Reserve, India
}

\author{
Rajeshwari Markam Nayak ${ }^{1}$, Kajal Kumar Jadav', Nidhi Rajput ${ }^{1 *}$, Sanjeev Gupta ${ }^{2}$, \\ Amol Rokde ${ }^{1}$ and Keshav Pratap Singh ${ }^{1}$ \\ ${ }^{1}$ School of Wildlife Forensic and Health, Nanaji Deshmukh Veterinary Science University, Jabalpur, Madhya Pradesh, INDIA \\ ${ }^{2}$ Panna Tiger Reserve, Panna, Madhya Pradesh, INDIA \\ *Corresponding author: N Rajput; E-mail: nidhi3rajput@gmail.com
}

Received: 24 Feb., 2020

Revised: 14 March, 2020

Accepted: 23 March, 2020

\begin{abstract}
The present study was conducted at Panna Tiger Reserve of Madhya Pradesh for sero-surveillance for canine parvovirus (CPV), canine distemper virus (CDV) and canine adenovirus (CAV) infections in feral dogs. Biological samples were also collected from the wild carnivore species which were immobilized or died during the study period. Serum samples were subjected for detection of IgG antibodies against CPV, CDV and CAV infections. Additionally biological samples of wild carnivores were subjected to molecular diagnosis of CPV and CDV genes. Seroprevalence for CPV, CDV and CAV infections was observed as $3.5 \%, 4.4 \%$ and $0.89 \%$, respectively, whereas for mixed infections of $\mathrm{CPV}+\mathrm{CDV}, \mathrm{CPV}+\mathrm{CAV}, \mathrm{CDV}+\mathrm{CAV}$ and $\mathrm{CPV}+\mathrm{CDV}+\mathrm{CAV}$, it was observed as $48.2 \%, 1.7 \%, 4.4 \%$ and $36.6 \%$, respectively. Sex wise, age wise and distance wise seroprevalence was nonsignificant in the present study. Seroprevalence for CPV, CDV and CAV infections in cats was observed as 50\%, $100 \%$ and $0 \%$, whereas in wild carnivores, it was observed as $100 \%, 90 \%$ and $0 \%$ respectively. PCR based diagnosis in the wild carnivore also revealed CDV positive cases. Serological and genomic evidence of pathogens in dogs-cats of buffer villages and wild carnivores of Panna tiger reserve indicated that the viruses may pose a high risk of spillover to wild carnivores. Study also indicated that dog population is immuned to major infectious diseases but can be a threat to the compromised wild carnivore species including tigers.
\end{abstract}

Keywords: Seroprevalence, spill-over infection, conservation, buffer zone

Canine distemper is an infectious disease caused by canine distemper virus (CDV), which is a RNA virus belonging to the genus Morbillivirus of the family Paramyxoviridae. The disease primarily infects canids but it has now been reported in other carnivores also. Canine distemper has received due attention because of the large scale mortalities in wild animals and outbreak of canine distemper in Serengeti lions and Amur tigers has resulted into researches on the virus for its spill-over to felidae (Funk et al., 2001). Three viral pathogens, canine parvovirus (CPV), canine distemper virus (CDV) and canine adenovirus (CAV), have a global distribution and cause severe, life-threatening diseases in feral dogs (Canis familiaris) and wild canid species (Day et al., 2010). Recent reporting of canine distemper in tigers and leopards in India has alerted the conservation authorities to investigate the source of spill-over in these wild species and subsequent death. Domestic carnivores living in the periphery of protected areas or tiger reserves have been suspected to be the source and in such situation, large scale vaccination programmes against canine distemper in the feral dogs or dogs living in the buffer villages have been recommended by National Tiger Conservation Authority, India. Recent reports of CPV seropositivity in one wild tiger (Chaudhary, 2015) and CDV and CAV induced mortality in Bengal foxes (Vulpes bengalensis) (Belsare et al., 2014) have raised concerns about infectious disease

How to cite this article: Nayak, R.M., Jadav, K.K., Rajput, N., Gupta, S. Rokde, A. and Singh, K.P. (2020). Surveillance of major canine pathogens in feral dogs and big cats at the domestic-wildlife interface in Panna tiger reserve, India. J. Anim. Res., 10(2): 303-308. 
threats to the wild carnivores in India. As most wildlife reserves in India are surrounded by human habitation with livestock-based economies, the frequency and intensity of interaction between dogs and wild carnivores is likely to be high.

Panna Tiger Reserve is located in Panna and Chhattarpur districts of Madhya Pradesh in India. The longitudinal and latitudinal location of the reserve stands between $24^{\circ} 43^{\prime} 49.60^{\prime \prime} \mathrm{N} 80^{\circ} 0{ }^{\prime} 36.80^{\prime \prime} \mathrm{E}$. The diversity in forest vegetation due to undulating terrains forms an ideal habitat for variety of wild animal species such as tiger, leopard, chital, chinkara, nilgai, sambar and sloth bear. Panna tiger reserve is surrounded by the buffer zone where villages are located. Economy of the villagers depends mainly over farming, livestock management and employment in wildlife tourism industry. However, villagers also suffer from economic losses due to livestock depredation by wild carnivores and crop raid by wild herbivores. Since wild carnivores move into the villages to predate on livestock and dogs, their interaction with dogs is marked. In buffer areas, dogs may be owned by individuals or affiliated with specific human habitations but much of their daily activity pattern involves free-ranging behaviour, and during the course of this ranging these animals have numerous opportunities to interact with wildlife at multiple levels, including as predators, prey, and competitors (Butler and DuToit 2002; Butler et al., 2004). Dogs in the villages are mostly feral that means they also move in the forest area without any human assistance. Such pattern allows frequent interactions between dogs and wild carnivores and subsequent spill-over of pathogens. There had been sporadic cases of canine distemper reported in the tigers in the region hence in this context, vaccination programme was started to cover the population of feral and buffer dogs against the canine pathogens including canine distemper. During the vaccination programme, our parallel study aimed at testing the population of dogs living in the buffer villages of Panna Tiger Reserve for antibodies against important canine pathogens before receiving the vaccine immunity. There are two antibodies mainly involved in the case of infectious disease, IgM and IgG antibodies. IgM antibodies are appeared in the early clinical stage and later replaced by IgG antibodies. IgG antibodies are indicative of passive immunity either achieved by vaccination or exposure to a pathogen. Current study focused on evaluation of feral dog samples for the presence of
IgG antibodies to know the level of exposure to canine pathogens. Additionally, wild species were also subjected for sampling opportunistically.

\section{MATERIALS AND METHODS}

\section{Study period}

The work was conducted during the period of July 2016 to March 2018. Field work was carried out at Panna Tiger Reserve, Madhya Pradesh and laboratory work was conducted at School of Wildlife Forensic and Health, Nanaji Deshmukh Veterinary Science University, Jabalpur, Madhya Pradesh.

\section{Study area}

The present work was conducted at Panna Tiger Reserve which is located in Panna and Chhattarpur districts of Madhya Pradesh in India. The longitudinal and latitudinal location of the reserve stands between $24^{\circ} 43^{\prime} 49.60^{\prime \prime} \mathrm{N}$ $80^{\circ} 0^{\prime} 36.80^{\prime}$ 'E. Panna tiger reserve is surrounded by buffer zone where approximately 75 villages are located. Economy of the villagers depends mainly over farming, livestock management and employment in wildlife tourism industry. However, villagers also suffer from economic losses due to livestock depredation by wild carnivores and crop raid by wild herbivores. Since wild carnivores move into the villages to predate on livestock and dogs, their interaction with dogs is marked.

\section{Sample collection}

The feral dogs found in the buffer villages of Panna Tiger Reserve were selected for the study. Based on the distance from core boundary, representative villages were selected as near $(<5 \mathrm{~km})$ and far $(\geq 5 \mathrm{~km})$. Dog population was estimated based on the records available with the forest department. The selection of villages and dogs for sampling was mainly dependent over the co-operation and priorities of the forest department. Dogs easily captured were subjected to sample collection irrespective of their abundance as the dogs were free-ranging and utmost care had to be taken while handling the dogs because of their unpredictable nature. Samples could be collected from total 112 dogs. Samples were also collected from the 
cats which were owned by the villagers and found to be in regular contact of dogs. Blood samples were collected from both the species and transported in cold chain to the laboratory for further analysis.

Additionally, biological samples were also collected from the wild carnivores, which are tigers and leopards, during the veterinary interventions for this research period. Blood and serum samples were collected from four tigers which were immobilized for necessary interventions. Whereas, necropsy samples such as conjunctival and rectal swabs were collected from the two leopards died during the study period and preserved in RNAlater (Qiagen). All these biological samples were also transported in cold chain to the laboratory for further analysis.

\section{Sero-surveillance of infectious diseases}

Collected serum samples were tested for the presence of IgG antibodies against canine parvo virus (CPV), canine distemper virus (CDV) and canine adeno virus (CAV) infections using BioGal's Immunocomb canine vaccichek kit (Bio Galed, kibbutz Galed, Israel, 192400). It semiquantifies antibodies and results are measured using a color comb scale according to the manufacturer's guidelines. Hence, S0 indicated sero-negative for antibodies and titers of and above $\mathrm{S} 1$ considered sero-positive for antibodies.

\section{Molecular detection of pathogen}

DNA was extracted from the blood samples and rectal swabs using QIAamp DNA mini kit (QIAGEN, GmBH, Hilden, Germany) and RNA was extracted from serum samples and conjunctival swabs using QIAamp Viral RNA mini kit (QIAGEN, GmBH, Hilden, Germany) according to the manufacturer's instructions. Thermo Scientific cDNA conversion kit (Thermo-Fisher Scientific, Bishop Road, Leicestershire, United Kingdom) was used to convert RNA into the cDNA.

The VP2 gene primers for CPV (forward primer, 5'-ACTATGCCATTTACTCCAGCT - 3'; reverse primer, 5' - TCCTGTAGCAAATTC ATC ACC -3') and NP gene primers for CDV (forward primer, 5' -AAC TAT GTA TCC GGC TCT TGG - 3'; reverse primer, 5' - CGA GTC TGAAGT AAG CTG GGT - 3') were used for PCR based detection. PCR was performed using 10 pmol of each primer. For $\mathrm{CPV}$ detection, the amplification parameters were $95^{\circ} \mathrm{C}$ for $2 \mathrm{~min}$ followed by 40 cycles of $95^{\circ} \mathrm{C}$ for 30 $\mathrm{s}, 52^{\circ} \mathrm{C}$ for $30 \mathrm{~s}$, and $72^{\circ} \mathrm{C}$ for $30 \mathrm{~s}$ with final extension at $72^{\circ} \mathrm{C}$ for $10 \mathrm{~min}$ prior to a $4^{\circ} \mathrm{C}$ hold. For CDV detection, the amplification parameters were $94^{\circ} \mathrm{C}$ for $1 \mathrm{~min}$ followed by 40 cycles of $94^{\circ} \mathrm{C}$ for $1 \mathrm{~min}, 59.5^{\circ} \mathrm{C}$ for $2 \mathrm{~min}$, and $72^{\circ} \mathrm{C}$ for $1 \mathrm{~min}$ with final extension at $72^{\circ} \mathrm{C}$ for $5 \mathrm{~min}$ prior to a $4{ }^{\circ} \mathrm{C}$ hold. The PCR products were resolved on $1 \%$ agarose gel and visualized under UV light in the presence of ethidium bromide dye.

\section{RESULTS AND DISCUSSION}

Human encroachment in the forest areas have resulted into fragmentation of habitat of wild species and increased interaction with domestic species and subsequent spill-over of infectious diseases. Panna Tiger Reserve is surrounded by number of villages where dogs are abundant and have access to the forest land. The present study was conducted to observe prevalence of antibodies to three viral pathogens, canine parvovirus (CPV), canine distemper virus (CDV) and canine adenovirus (CAV), in free-ranging or feral dogs, cats as well as wild felids in and around the tiger reserve. The study revealed that the feral dog populations around Panna Tiger Reserve had high exposure rates to $\mathrm{CPV}, \mathrm{CDV}$ and $\mathrm{CAV}$ infections suggesting active circulation of these pathogens in the dog populations. Similar observations have also been reported in other systems as well such as GIB Wildlife Sanctuary (Maharashtra) and Kanha Tiger Reserve (Madhya Pradesh) where there were high exposure to these pathogens observed in unvaccinated rural dog populations (Belsare et al., 2014; Chaudhary et al., 2018). Studies on the other continents had also revealed similar observations (Cleaveland et al., 2000; Acosta-Jamett et al., 2015).

\section{Sero-prevalence of CPV, CDV and CAV infections}

There were mixed infections of all these three pathogens more prevalent over infection of a single pathogen (Table 1). In the present study, approximately $92 \%$ of dogs were found to be exposed to one or more of the three pathogens. There was a close association of CPV and CDV infections and similar pattern was also observed for mixed infection of CPV, CDV and CAV. This might be because of the reasons including common transmission routes, immunosuppression and secondary infection. High sero-prevalence of CPV and CDV suggests that the virus 
is endemic and the exposed dog population may serve as a reservoir for the pathogen. Seroprevalence of CAV was relatively low and hence transmission of this pathogen can be assumed as low in the region.

Table 1: Number of total dogs tested and observed seroprevalence in each category for canine parvovirus (CPV), canine distemper virus (CDV), canine adenovirus (CAV) mono and mixed infections

\begin{tabular}{lll}
\hline $\begin{array}{l}\text { Samples (n=112) tested for } \\
\text { the presence of antibodies } \\
\text { against infections }\end{array}$ & $\begin{array}{l}\text { Number of dogs } \\
\text { positive (n) }\end{array}$ & $\begin{array}{l}\text { Prevalence } \\
(\%)\end{array}$ \\
\hline CPV & 04 & 3.50 \\
CDV & 05 & 4.40 \\
CAV & 01 & 0.89 \\
CPV+CDV & 54 & 48.20 \\
CPV+CAV & 02 & 1.70 \\
CDV+CAV & 05 & 4.40 \\
CPV+CDV+CAV & 41 & 36.60 \\
\hline
\end{tabular}

\section{Sex wise prevalence of CPV, CDV and CAV infections}

Out of 112 dogs tested, 79 animals were male and 33 animals were females. Among male individuals, prevalence for $\mathrm{CPV}, \mathrm{CDV}$ and $\mathrm{CAV}$ were recorded as $86.07 \%, 93.6 \%$ and $44.3 \%$, respectively. Whereas among females, prevalence were recorded as $96.9 \%, 87.8 \%$ and $39.3 \%$ for CPV, CDV and CAV, respectively. Chi-square test analysis proved that differences in sex-wise prevalence were non-significant. Our studies suggested that there were no significant relationships of sex of individuals with the prevalence of the three pathogens. In contrast, Belsare et al. (2014) recorded prevalence of CDV greater in females, although, no specific reason was given to justify the relationship.

\section{Age wise prevalence of CPV, CDV and CAV infections}

Out of 112 dogs tested, 29 animals were young (below 1 year) and 83 animals were adults (above 1 year). Prevalence were recorded as $93.1 \%, 89.6 \%$ and $31.0 \%$ in young animals whereas $87.9 \%, 92.7 \%$ and $46.9 \%$ in adult animals for CPV, CDV and CAV, respectively. Chi-square test analysis proved that differences in age-wise prevalence were non-significant. This was in contrast to the results shown by Belsare et al. (2014) and Chaudhary et al. (2018) who conducted the studies based on breeding season and found juveniles to be more susceptible to infection. Our results suggested lifelong immunity however, because of the high breeding efficacy of the dogs, pack immunity cannot be maintained and there are always chances of disease occurrence at any point of time.

\section{Distance wise prevalence of CPV, CDV and CAV infections from core boundary}

Buffer villages were divided into two groups based on the distance from the core boundary as near (Distance from the core boundary $<5 \mathrm{KM}$ ) and far (Distance from the core boundary $>5 \mathrm{KM}$ ) villages. Out of 112 dogs tested, 56 animals were from near villages and 56 animals were from far villages. Prevalence rate for CPV, CDV and CAV was recorded as $92 \%, 96.4 \%$ and $39.2 \%$ in near villages whereas it was $85.7 \%, 86.5 \% 46.4 \%$ respectively in far villages. Chi-square test analysis proved that differences in distance-wise prevalence were non-significant. The results are in contrast to the results shown by Chaudhary et al. (2018), where villages were divided into near $(<2$ K.M. from core boundary) and far $(<6$ K.M. from core boundary) and seroprevalence was significant in far villages for CDV and CAV infections and in near villages for CPV infection. This study indicated that dogs and wild carnivores are at risk of introduced infection whereas our study indicated that these pathogens are uniformly distributed in the villages situated in the buffer zone of Panna Tiger Reserve. The results highlighted the presence of these pathogens as a threat of spill-over to the wild carnivores interacting with feral dogs.

\section{Species wise prevalence of CPV, CDV and CAV infections}

Other than dogs, samples from domestic cats and tigers were also analyzed for sero-prevalence against canine pathogens. Antibodies against $\mathrm{CPV}$ and $\mathrm{CDV}$ were observed in all the three species however domestic cats and tigers did not show the presence of antibodies against CAV.

\section{Molecular detection of pathogens}

Polymerase Chain Reaction (PCR) based diagnosis of $\mathrm{CPV}$ and CDV was performed only in the samples of the 
wild felids. The analysis revealed no positive results for CPV infection, however, conjunctival samples from the two leopards were found positive for CDV infections (Table 2 and Fig. 1).

Table 2: Number of wild felids tested (n) and positive (n) in each category for PCR based detection of canine parvovirus $(\mathrm{CPV})$ and canine distemper virus (CDV) infections

\begin{tabular}{lllll}
\hline $\begin{array}{l}\text { SI. } \\
\text { No. }\end{array}$ & Infection & $\begin{array}{l}\text { Species of } \\
\text { animal }\end{array}$ & $\begin{array}{l}\text { Number of } \\
\text { animals tested } \\
\text { (n) }\end{array}$ & $\begin{array}{l}\text { Number of } \\
\text { animals positive } \\
\text { by PCR (n) }\end{array}$ \\
\hline 1 & CPV & Tiger & 4 & 0 \\
& & Leopard & 2 & 0 \\
2 & \multirow{2}{*}{ CDV } & Tiger & 4 & 0 \\
& & Leopard & 2 & 2 \\
\hline
\end{tabular}

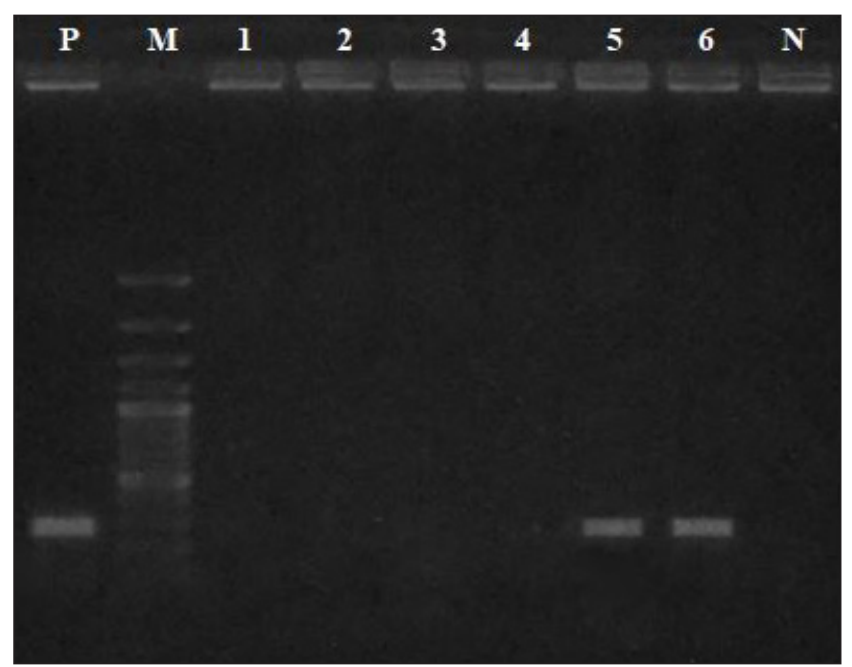

Fig. 1: PCR based detection of CDV infection in wild carnivores. Lane P - Positive control (260bp), Lane M - 100bp marker, Lane 1-4 - Test samples (Tiger), Lane 5-6 - Test samples (Leopard), Lane N - Negative control

Serological and genomic evidences of pathogens in dogscats of buffer villages and wild carnivores of Panna tiger reserve indicates that the viruses may pose a high risk of spillover to wild carnivores. Endangered carnivores like tigers are particularly vulnerable to these infectious diseases because of their small population size, limited genetic diversity and inadequate geographical distribution. However, for efficient screening, regular sero-surveillence in domestic, meso and wild carnivore species is strongly recommended. Mesocarnivores, like hyena, jackals, and foxes can be a source population for infectious agent to core carnivores, hence detailed studies on the species is mandatory for conclusive remark. Additionally, broader and long-term sampling from the buffer and core carnivore species is required to determine the threats and confirmed chances of spillover.

\section{CONCLUSION}

Nevertheless, present study indicates that dog population is immuned to major infectious diseases but can be a threat to the compromised wild carnivore species. These findings suggest scientific management of dog population in the periphery of Panna Tiger Reserve to control the disease occurrence which may include population control and further interventions.

\section{ACKNOWLEDGEMENTS}

Authors are thankful to the Field Director, Panna Tiger Reserve, Madhya Pradesh for providing the necessary logistic and support during the field work.

\section{REFERENCES}

Acosta-Jamett, G., Cunningham, A.A., Bronsvoort, B.M.C. and Cleaveland, S. 2015. Serosurvey of canine distemper virus and canine parvovirus in wild canids and domestic dogs at the rural interface in the Coquimboregion, Chile. Euro. J. Wildl. Res., 61: 329-332.

Belsare, A.V, Vanak, A.T. and Gompper, M.E. 2014. Epidemiology of viral pathogens of free-ranging dogs and Indian foxes in a human-dominated landscape in central India. Transbound. Emerg. Dis., 61: 78-86.

Butler, J.R.A. and duToit, J.T. 2002. Diet of free-ranging domestic dogs (Canis familiaris) in rural Zimbabwe: implications for wild scavengers on the periphery of wildlife reserves. Anim. Conserv., 5: 29-37.

Butler, J.R.A., duToit, J.T. and Bingham, J. 2004. Free-ranging domestic dogs (Canis familiaris) as predators and prey in rural Zimbabwe. Threats of competition and disease to large wild carnivores. Biol. Conserv., 115: 369-378.

Chaudhary, V. 2015. Threats of disease spillover from domestic dogs to wild carnivores in the Kanha tiger reserve, India. M.S. thesis (Biological Sciences), Clemson University, South Carolina, USA.

Cleaveland, S., Appel, M.G.J., Chalmers, W.S.K., Chillingworth, C., Kaare, M. and Dye, C. 2000. Serological and demographic evidence for domestic dogs as a source of canine distemper 
virus infection for Serengeti wildlife. Vet. Microbiol., 72: 217-227.

Day, M., Horzinek, M. and Schultz, R. 2010. WSAVA guidelines for the vaccination of dogs and cats. J. Small Anim. Pract., 51: $338-356$
Funk, S.M., Fiorello, C.V., Cleaveland, S. and Gompper, M.E. 2001. The role of disease in carnivore ecology and conservation. In: Carnivore Conservation, (Eds) Gittleman, J.L., Funk, S.M, MacDonald, D.W. and Wayne, R.K., Cambridge University Press, UK. pp. 443-466. 